\title{
Weight six years after childbirth: a follow-up of obese women in a weight-gain restriction programmme
}

\author{
Ing-Marie Claesson, Ann Josefsson and Gunilla Sydsjö
}

\section{Linköping University Post Print}

\section{Tweet}

N.B.: When citing this work, cite the original article.

Original Publication:

Ing-Marie Claesson, Ann Josefsson and Gunilla Sydsjö, Weight six years after childbirth: a follow-up of obese women in a weight-gain restriction programmme, 2013, Midwifery.

http://dx.doi.org/10.1016/j.midw.2013.06.009

Copyright: Elsevier http://www.elsevier.com/

Postprint available at: Linköping University Electronic Press http://urn.kb.se/resolve?urn=urn:nbn:se:liu:diva-102279 
Ing-Marie Claesson RNM, PhD, Ann Josefsson MD, PhD, Gunilla Sydsjö PhD

Division of Obstetrics and Gynecology, Department of Clinical and Experimental Medicine, Faculty of Health Sciences, Linköping University, Department of Obstetrics and Gynecology in Linköping, County Council of Östergötland, Linköping, Sweden

\section{WEIGHT SIX YEARS AFTER CHILDBIRTH: A FOLLOW-UP OF OBESE WOMEN IN A WEIGHT-GAIN RESTRICTION PROGRAM}

\section{Correspondence:}

Ing-Marie Claesson

Division of Obstetrics and Gynecology

Department of Clinical and Experimental Medicine

Faculty of Health Sciences

Linköping University

SE - 58183 Linköping, Sweden

Tel. +46101032923

Fax: +4613148156

Email: Ing-Marie.Claesson@liu.se 


\section{Abstract}

Objective: to compare weight development in an intervention group and a control group, six years after participation in a gestational weight-gain restriction programme.

Design: follow-up of a prospective intervention study.

Settings: antenatal care clinics.

Participants: a total of 129 women $(88.4 \%)$ from the original intervention group and 166 women $(88.8 \%)$ from the original control group.

Measurements: the women answered a study specific questionnaire, covering sociodemographic data and health- and weight status.

Findings: After adjusting for socio-demographic factors, the mean weight was lower $(4.1 \mathrm{~kg})$ among the women in the intervention group, compared to the controls $(\mathrm{p}=0.028)$.

Furthermore, the mean weight change, e.g. the weight at the six year assessment compared with the weight at the start of the intervention at the first antenatal care visit, was greater in the intervention group than in the control group. The women in the intervention group had a larger mean weight change $(-5.2 \mathrm{~kg})$, e.g. weighed less than the women in the control group ($1.9 \mathrm{~kg})(\mathrm{p}=0.046)$. Mean weight change expressed in $5 \mathrm{~kg}$ classes also showed a significant difference between the two groups $(\mathrm{p}=0.030)$.

Key conclusions: the results indicate that attending a gestational weight-gain-restriction programme can have a positive effect on weight up to six years after the intervention.

Implication for practise: a restrictive gestational weight gain can result in a positive weight development during the first years after childbirth. It might provide both short- and long term medical health benefits for the mother as well as the child.

Keywords: Obesity, Pregnancy, Weight gain, Intervention studies. 


\section{Introduction}

Obesity poses a high risk for complications during pregnancy and delivery and also for the fetus/infant and an excessive gestational weight gain may further increase the risk (Bodnar et al., 2010, Tsoi et al., 2010, Blomberg and Kallen, 2010, Blomberg, 2011, Tennant et al., 2011). A large weight gain during pregnancy may result in large weight retention post partum and several years later (Linne et al., 2004, Rooney and Schauberger, 2002, Rooney et al., 2005). Linne et al.,(2004) showed in a 15-year follow-up study, encompassing 563 participants, that women with high gestational weight gain and high weight retention during the post partum year had a higher body mass index (BMI) 15 years later. Rooney and Schauberger (2002) and Rooney et al., (2005) followed a cohort of 500 women through pregnancy and reported results from 8-year and 15-year follow-up studies. The average weight gain was slightly more than six kilos and almost ten kilos from pre-pregnancy to the follow-up assessment eight and 15 years later, respectively. Excess gestational weight gain and failure to lose weight after pregnancy have been reported to be important predictors of long-term obesity in women (Rooney and Schauberger, 2002, Rooney et al., 2005). Women who gained more weight than recommended by the Institute of Medicine (IOM), and retained that weight six months post partum weighed 2-4 kg more at the 8-year follow-up, compared with women who gained the recommended amount or less and with women who lost all the weight gained during pregnancy (Rooney and Schauberger, 2002, Institute of Medicine. Subcommittee on Nutritional et al., 1990). The gestational weight gain advice given of Institute of Medicine, 1990 was broad and the range extends from at least $6.8 \mathrm{~kg}$ for women with BMI $>29 \mathrm{~kg} / \mathrm{m}^{2}$ to an upper limit of $18.0 \mathrm{~kg}$ for BMI $<19.8 \mathrm{~kg} / \mathrm{m}^{2}$. In 2009 these guidelines were re-examined and the new recommendations were now based on WHO BMI classes and included a specific and relatively narrow range of suggested gestational weight gain for obese women $\left(B M I \geq 30 \mathrm{~kg} / \mathrm{m}^{2}: 5.0-9.1 \mathrm{~kg}\right.$ ) and the same upper limit of $18.0 \mathrm{~kg}$ for underweight pregnant women as before (Rasmussen et al., 2009).

During the last decade the importance of intervention programmes for obesity and weightgain prevention have been in focus and several intervention studies have been conducted (Polley et al., 2002, Olson et al., 2004, Kinnunen et al., 2007, Wolff et al., 2008, Quinlivan et al., 2011, Shirazian et al., 2010, Phelan et al., 2011). Four of these studies encompassed obese pregnant women (Wolff et al., 2008, Guelinckx et al., 2010, Quinlivan et al., 2011, Shirazian et al., 2010). The intervention was associated with a reduced gestational weight gain in the studies by Wolff et al., (2008), Quinlivan et al., (2011) and Shirazian et al.,(2010), whereas Guelinckx et al., (2010) reported no difference in weight gain. We have shown in a previous 
study that an intervention programme aiming to minimise the gestational weight gain to less than $7 \mathrm{~kg}$, was effective (Claesson et al., 2008). In the 2-year follow-up after the index birth, the women who reached the target i.e. $<7 \mathrm{~kg}$ did benefit from the intervention and weighed less compared to the women in the control group (Claesson et al., 2010). The aim of this follow-up study was to assess weight development in the intervention- and control groups six years after participation in a weight-gain-restriction programme. 


\section{Methods}

The original study was conducted at the antenatal care clinic (ANC) in Linköping and at ANCs in two nearby cities from November 2003 to December 2005. This study is described elsewhere and summarized briefly below (Claesson et al., 2008). All obese (BMI $\geq 30 \mathrm{~kg} / \mathrm{m}^{2}$, $\mathrm{n}=317$ ) pregnant women who registered in early pregnancy at the ANC in the city of Linköping and surroundings were offered the chance to participate in an intervention study with the aim to minimize the gestational weight gain to less than $7 \mathrm{~kg}$. The exclusion criteria were inability to understand Swedish, a diagnosis of pre-pregnant diabetes, thyroid dysfunction or a psychiatric disease treated with neuroleptic drugs; and 45 women were therefore excluded from participation. Twenty women moved out of the area during pregnancy and 13 women who had early spontaneous or legal abortion were also excluded. Of the 230 remaining women, 70 women chose not to participate and five dropped out during pregnancy. Finally, 155 women $(67.4 \%)$ completed the study. The women were offered extra visits - 30 minutes every week - with a specially trained midwife with the aim of motivating them to change behaviours regarding nutrition and physical activity. They were also invited to join aqua aerobic classes once or twice a week, classes especially designed for obese women. As controls for these women all obese pregnant women $(n=437)$ in two nearby cities were offered the chance to participate in the study. The inclusion- and exclusion criteria were the same as for the intervention women. Forty-two women did not meet the inclusion criteria and were therefore excluded from participation. Ten women had a miscarriage or legal abortion. Finally, 385 women were eligible and invited to participate. Of this a total, 177 women refrained from participation and 15 women dropped out. One hundred ninety-three women $(50.1 \%)$ completed the participation.

The intervention programme was effective. The women belonging to the intervention group gained $8.7 \mathrm{~kg}$ during their pregnancies, compared with the women in the control group who gained $11.3 \mathrm{~kg}(\mathrm{p}<0.001)$. The sub-group of the women who gained $<7 \mathrm{~kg}$ was greater in the intervention group (35.7\%), than in the control group $(20.5 \%)(\mathrm{p}=0.003)$. At the postnatal check-up there was still a significant difference between the groups. The women in the intervention group weighed $2.2 \mathrm{~kg}$ less than the weight in early pregnancy, whereas the corresponding figure in the control group was $0.8 \mathrm{~kg}(\mathrm{p}<0.001)$ (Claesson et al., 2008). At the 2-year follow-up there was a remaining weight difference among the women who gained $<7$ $\mathrm{kg}$ during their pregnancies. The women belonging to the intervention group weighed $13.5 \mathrm{~kg}$ less than the women in the control group ( $\mathrm{p}=0.018)$ (Claesson et al., 2010). 


\section{Subjects in this study}

All women from the original study were asked to participate in this follow-up study, six years after the index pregnancy. The study was approved by the Regional Ethical Review Board in Linköping (reference number 2010/400-31) and all subjects gave informed consent.

A study specific questionnaire was constructed by the authors and included information about parity, marital status, occupation status, education level, smoking habits, health status and current weight status, were sent by post to 347 women. Each woman's personal identity number was used to obtain her current address. All the women were found. One woman had protected personal data and it was therefore not possible to reach her. A reminder was sent after four weeks.

Concerning current weight status the women were asked to note if the weight given was newly measured or estimated and regarding health status each was asked to specify if she suffered from a chronic or serious illness.

Answers were received from 147 women in the intervention group. A total of nine women were excluded because of on-going pregnancy, postnatal period (e.g. $<12$ months after giving birth) or illness. Nine women refrained from participation. One hundred twenty nine women $(88.4 \%)$ took part in the follow-up study. A total of 187 women belonging to the control group answered the questionnaire. Because of on-going pregnancy, postnatal period or illness six women were excluded and 15 women chose not to participate, thus 166 women $(88.8 \%)$ participated in the follow-up. The description of the population in the original and follow-up studies is displayed in Figure 1. 


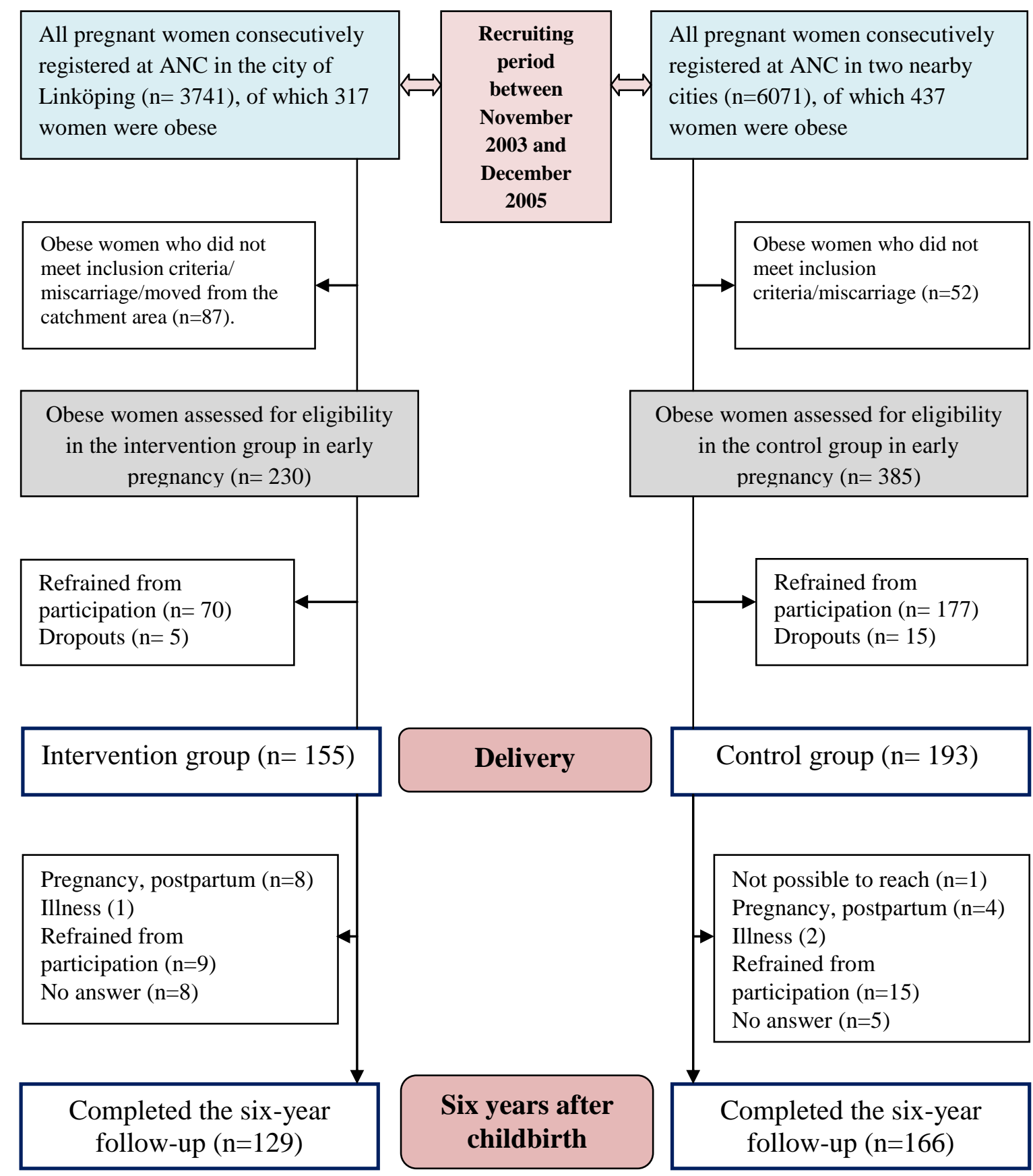

Figure1. Description of the population in the original- and follow-up studies

\section{$\underline{\text { Statistics }}$}

All analyses were performed using the IBM SPSS program, version 19.0 (IBM Corp., Armonk, NY, USA). Statistical significance was defined as (two-sided) $\mathrm{p} \leq 0.05$. Before 
analysing the weight changes, the assumption of these variables being normally distributed was validated using the Kolmogorov-Smirnov test. Since this assumption was confirmed, an ordinary Student's $t$-test was used as method of analysis for detecting weight change differences between intervention and control women six years after index pregnancy. In general, group differences were estimated by using the $\mathrm{x}^{2}$ test on categorical variables and the Student's $t$ test on continuous, normally distributed variables. Furthermore, to make a more comprehensive assessment of group differences, linear regressions were performed with the weight as dependent variables. The grouping variable has been adjusted for sociodemographic characteristics (age, parity, tobacco user).

\section{Findings}


The average time of the follow-up among the women in the intervention- and control group was six years. The socio-demographic data at the time for follow-up are displayed in Table 1.

Table 1. Socio-demographic characteristics for the women in the intervention- and control group at the time of the 6-year follow-up

\begin{tabular}{|c|c|c|c|c|c|c|}
\hline & & \multicolumn{2}{|c|}{$\frac{\text { Intervention }}{\text { group }}$} & \multicolumn{2}{|c|}{ Control group } & \multirow[b]{2}{*}{$p$} \\
\hline & & $\mathrm{N}$ & $\%$ & $\mathrm{~N}$ & $\%$ & \\
\hline Age; mean $(\mathrm{SD})^{*}$ & & $\begin{array}{l}30.3 \\
(4.4)\end{array}$ & & $\begin{array}{l}30.7 \\
(4.7)\end{array}$ & & 0.366 \\
\hline Parity** & $\begin{array}{r}1 \\
2 \\
\geq 3\end{array}$ & $\begin{array}{c}9 \\
81 \\
39\end{array}$ & $\begin{array}{c}7.0 \\
62.8 \\
30.2\end{array}$ & $\begin{array}{l}24 \\
90 \\
52\end{array}$ & $\begin{array}{l}14.5 \\
54.2 \\
31.3\end{array}$ & 0.101 \\
\hline
\end{tabular}

Marital status**

Married/cohabiting

113

87.6

143

0.912

Single mother

$13 \quad 10.1$

18

86.1

Other situation

3

2.3

$5 \quad 3.0$

Tobacco users**

$\begin{array}{rcccc}\text { No } & 119 & 93.0 & 135 & 81.3 \\ \text { Yes } & 9 & 7.0 & 31 & 18.7\end{array}$

\section{Occupation status**}

Gainfully employed

Unemployed

On parental leave

Student

Sick-leave

Other situation

$\begin{array}{cccc}107 & 82.9 & 135 & 81.3 \\ 9 & 7.0 & 9 & 5.4 \\ 4 & 3.1 & 5 & 3.0 \\ 4 & 3.1 & 7 & 4.2 \\ 1 & 0.8 & 7 & 4.2 \\ 4 & 3.1 & 3 & 1.8\end{array}$

Education level, year**

$\begin{array}{rcccc}\leq 9 & 5 & 3.9 & 10 & 6.0 \\ 10-12 & 66 & 51.2 & 91 & 54.8 \\ \geq 13 & 58 & 45.0 & 65 & 39.2\end{array}$

0.490

\footnotetext{
* Student's $t$-test

***Chi ${ }^{2}$-test
}

More women in the control group used tobacco, compared with the intervention group $(\mathrm{p}=0.004)$. 
Table 2 shows that women in the intervention group more often gave birth to another child after the index pregnancy than did the women in the control group $(\mathrm{p}=0.016)$.

Table 2. Giving birth before and/or after the index pregnancy among the women in the intervention- and control group.

\begin{tabular}{|c|c|c|c|c|c|}
\hline & \multicolumn{2}{|c|}{$\begin{array}{c}\text { Intervention } \\
\text { group } \\
n=129\end{array}$} & \multicolumn{2}{|c|}{$\begin{array}{c}\text { Control } \\
\text { group } \\
n=166\end{array}$} & \multirow[b]{2}{*}{$\mathrm{p}^{*}$} \\
\hline & $\mathrm{n}$ & $\%$ & $\mathrm{n}$ & $\%$ & \\
\hline Giving birth before the index pregnancy & & & & & 0.77 \\
\hline No & 57 & 44.2 & 73 & 44.0 & \\
\hline 1 child & 58 & 45.0 & 60 & 36.1 & \\
\hline$\geq 2$ children & 14 & 10.9 & 33 & 19.9 & \\
\hline Giving birth after the index pregnancy & & & & & 0.016 \\
\hline $\int_{0}^{0}$ & 65 & 50.4 & 110 & 66.3 & \\
\hline 1 child & 58 & 45.0 & 48 & 28.9 & \\
\hline$\geq 2$ children & 6 & 2.0 & 8 & 2.7 & \\
\hline $\begin{array}{l}\text { Giving birth before and after the index } \\
\text { pregnancy }\end{array}$ & & & & & 0.120 \\
\hline Yes & 23 & 17.8 & 19 & 11.4 & \\
\hline No & 106 & 82.2 & 147 & 88.6 & \\
\hline
\end{tabular}

* $\mathrm{Chi}^{2}$-test

Table 3 shows the mean weight at the follow-up assessment and the weight change between the time of the recruitment, i.e. at the beginning of pregnancy and the follow-up occasion. The women in the intervention group weighed $4.1 \mathrm{~kg}$ less than the women in the control group ( $\mathrm{p}=0.017$ ). The mean weight change from the first weight measured in early pregnancy to the follow-up assessment after six years showed that the women in the intervention group had a mean weight change of $-5.2 \mathrm{~kg}$, compared with the women in the control group who had a mean weight change of $-1.9 \mathrm{~kg}(\mathrm{p}=0.031)$. After adjustment for socio-demographic characteristics the differences between the two groups remained. 
Table 3. Weight and weight change at the 6-year follow-up among the studied women in the intervention- and control group.

\section{Intervention group Control group}

\begin{tabular}{|c|c|c|c|c|c|c|c|c|}
\hline & $\mathrm{N}$ & Mean* & SD & $\mathrm{N}$ & Mean* & SD & $p^{* *}$ & $p^{* * *}$ \\
\hline $\begin{array}{l}\text { Weight in early } \\
\text { pregnancy } \dagger\end{array}$ & 129 & 94.6 & 11.280 & 166 & 95.6 & 15.080 & 0.545 & \\
\hline $\begin{array}{l}\text { Weight at six years after } \\
\text { childbirth }\end{array}$ & 128 & 89.5 & 13.140 & 164 & 93.6 & 15.494 & 0.017 & $0.028 \dagger \dagger \dagger$ \\
\hline $\begin{array}{l}\text { Weight change from } \\
\text { early pregnancy to six } \\
\text { years after childbirth } \dagger \dagger\end{array}$ & 128 & -5.2 & 11.090 & 164 & -1.9 & 13.405 & 0.031 & $0.046 \ddagger$ \\
\hline
\end{tabular}

Weight gain $<7 \mathrm{~kg}$ during

pregnancy

Weight in early

pregnancyt

$\begin{array}{lllllll}42 & 94.1 & 10.921 & 32 & 97.8 & 16.348 & 0.267\end{array}$

Weight at six years after childbirth

$\begin{array}{lllllll}42 & 87.0 & 9.601 & 31 & 92.0 & 16.676 & 0.146\end{array}$

Weight change from

early pregnancy to six years after childbirth $\dagger \dagger$

$\begin{array}{lllllll}42 & -7.0 & 11.495 & 31 & -6.0 & 14.934 & 0.740\end{array}$

* Mean expressed in kilograms.

** Student's $t$-test.

*** Linear regression, adjusted for socio-demographic factors

$\dagger$ Weight at the recruitment in the study.

$\dagger$ Weight at the follow-up occasion 'minus' weight at the recruitment in the study.

$\dagger \dagger p($ age $)=0.112, p$ (parity) $=0.854, p($ tobacco user $)=0.859$,

$\ddagger p($ age $)=0.745, p($ parity $)=0.701, p($ tobacco user $)=0.514$, 
Figure 2 shows the weight development i.e. the weight six years after the index pregnancy compared with the weight at the first antenatal care visit, expressed in $5 \mathrm{~kg}$ classes. More women in the intervention group had lost weight compared with women in the control group $(\mathrm{p}=0.030)$. There was no difference in mean BMI between the two groups (data not shown). A total of $30.5 \%$ of the women in the intervention group and $24.4 \%$ in the control group showed a BMI $<30$ at the six year follow-up. Three women in the intervention group and two women in the control group had reached a BMI $<25$.

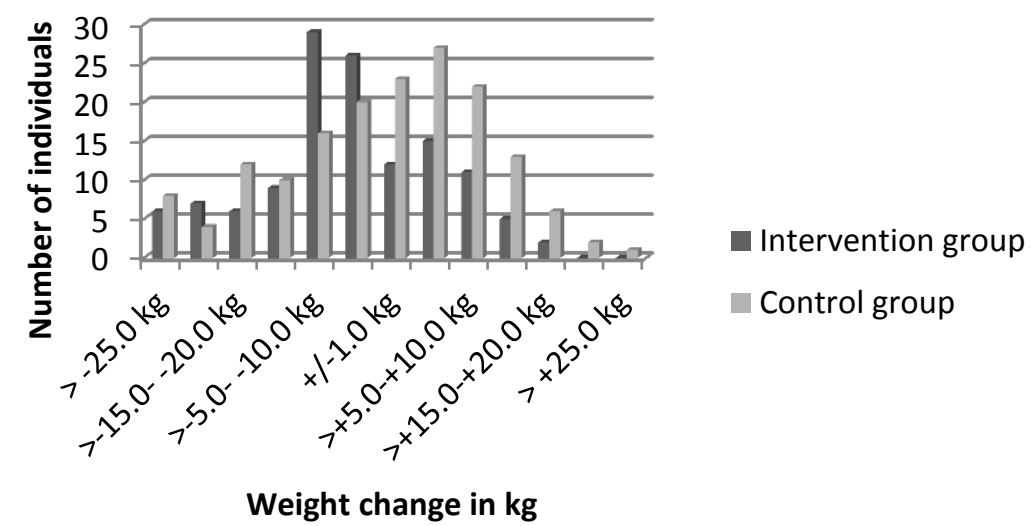

Figure 2. Weight change six years after childbirth during the study period in the intervention- and control group, compared with weight at the first antenatal care clinic visit.

Concerning the mean weight change, there were two women, one in each group, who showed a very large weight difference between the assessment in early pregnancy and the follow-up occasion (-50.6 kg and $-64.0 \mathrm{~kg}$ respectively). In a secondary analysis we excluded these women but this step did not change the results, therefore they are still included.

Four women in the intervention group and seven women in the control group had undergone bariatric surgery after the index pregnancy. Of these, two women in the intervention group and five women in the control group had lost weight, $>25 \mathrm{~kg}$.

Analysis of the subgroups that had gained less than seven kilos during pregnancy shows no difference between the intervention and control group (Table 3).

\section{Discussion}


In this study we investigated the possible long term effect of a weight-gain restriction programme during pregnancy. The women in the intervention group had a significantly lower mean weight than the women in the control group six years after participation. In terms of weight changes, that is, the weight after six years compared with the weight at the first antenatal care visit as expressed in $5 \mathrm{~kg}$ classes, there were significant differences between the weights at the two assessments. The women in the intervention group had a greater mean weight change and furthermore, a greater percentage of women in the intervention group had lost weight than in the control group. Concerning the women who had a gestational weight gain of less than seven kilos there was no difference between the groups.

In our 2-year follow-up study we found no difference in mean weight or mean weight change between the intervention and control groups (Claesson et al., 2010). The present study, with a higher rate of participation, shows a lower weight six years after childbirth among both women in the intervention- and control group, compared with their weight in early pregnancy. However, the mean weight in the intervention group was significant lower than in the control group. On the other hand, there is no difference, six years after the index pregnancy, between the two sub-groups that had a gestational weight gain less than $7 \mathrm{~kg}$. This is in contrast with our findings in the 2-year follow-up, which showed a significant difference between the groups (Claesson et al., 2010). The women in the intervention group had a lower mean weight at the time of that assessment than the women in the control group. One can speculate about the optimal time interval at which assessment of postnatal weight change should be made and thus question if assessment only two years after childbirth is being done too early? Gunderson and Abrams (1999) discuss this topic in a review. Data on pregnancyrelated weight changes at specific post partum intervals are limited so further research is desirable. It is possible that women who become pregnant within a short period of time or more than once in five years constitute a group most likely to be at risk for excessive weight gain (Gunderson and Abrams, 1999). Lipsky et al.,(2012) argue in a recent study that it is important to differentiate between 'weight retention' (one year post partum) and a potential risk for late post partum weight gain (one to two years post partum). Davis et al. (2013) investigated the relationship between parity, length of inter-pregnancy interval, excessive gestational weight gain during the first pregnancy and the risk for obesity in a prospective cohort of 3400 non-obese and non-pregnant American women, who were followed for nine years. The results showed that excessive weight gain during the first pregnancy and interpregnancy interval less than 12 month increased the risk obesity (Davis et al., 2013). In our 
study half of the women in the intervention group and one third of the women in the control group had given birth to one additional child or more after the index pregnancy, but the mean weight in the intervention group as well as the control group was lower at the 6-year assessment compared with the weight in early pregnancy. Postnatal life involves major changes in lifestyle and behaviour such as a new family constellation, the maternal role, decreased physical activity, changes in meal habits, eating less healthy foods and a greater access to food (Ohlin and Rossner, 1996, Harris et al., 1999, Ostbye et al., 2012). It is likely that the influence of gestational weight gain may be greatest during the first year post partum and that other factors may be more important in determining long-term weight changes (Gunderson and Abrams, 1999). In our study, six years after the index pregnancy, there were significant differences in mean weight and mean weight changes between the two groups. One can therefore speculate about the impact of the intervention programme during pregnancy that seems to still affect weight development after pregnancy. But it is also possible that life itself is more balanced six years later, in spite of the fact that some of the women still are in this hectic phase of being parents of small children. The cornerstone in the intervention programme was the motivational talk according to the methodology of motivational interviewing [MI] (Miller and Rollnick, 2002). MI is a change-oriented conversional approach in order to find ways to make changes in behaviour. It is possible that confidence to cope with new lifestyle habits, i.e. a good energy balance, persist a long time after the study participation. Therefore, MI seems to be one effective method but also dietary and physical interventions during pregnancy have shown to be effective reducing gestational weight gain (Thangaratinam et al., 2012).

A number of studies report results concerning weight change at different times after childbirth (Linne et al., 2004, Rooney and Schauberger, 2002, Rooney et al., 2005, Mamun et al., 2010, Olson et al., 2004, Amorim et al., 2007, Maddah and Nikooyeh, 2009). Olson et al., (2004) monitored 560 normal and overweight women in an intervention group. The gestational weight gain was monitored by health-care providers and then compared with a historical control group from early pregnancy until one year after childbirth. They found no difference in weight gain or weight retention. Rooney and Schauberger, (2002) followed 500 women through pregnancy and six months post partum and made an assessment 8.5 year later. The average weight gain from pre-pregnancy to the follow-up assessment was $6.3 \mathrm{~kg}$. The results of these two studies are not in accordance with the results of our six-year followup. The women in both the intervention and the control groups weighed less after six years than they weighed in early pregnancy. In another study by Rooney et al., (2005) the weight 
gain in relation to different BMI classes was analysed. The weight gain was more pronounced for women who were obese in early pregnancy, compared with those who were under-, normal- or overweight. Obese women were on average $15.5 \mathrm{~kg}$ heavier 15 years later (Rooney et al., 2005). In a recent Australian study the long-term effect of gestational weight gain, based on the IOM recommendations, was examined 21 years after the index pregnancy (Mamun et al., 2010). The women who gained more than the recommended level during pregnancy ran a more than two-fold risk of being overweight 21 years later. The corresponding odds for being obese were 4.5 (Mamun et al., 2010). Amorim et al., (2007) report similar results in a 15-year follow-up study. Gestational weight gain was related to BMI at the follow-up assessment. Women who gained excessive weight during pregnancy had a higher long-term BMI compared with women who gained within the IOM recommendations (Amorim et al., 2007). Maddah and Nikooyeh, (2009) also found that Iranian women, who during pregnancy gained more weight than recommended, weighed more than women who gained within suggested ranges, three years after childbirth.

This study has strengths as well as weaknesses. The rate of participation is high in both the intervention group and in the control group. One can speculate over the reason for the high rate of participation in the follow-up study. It is possible that our sincere aim to help and support obese pregnant women in a change process has encouraged these women to continue participation. Furthermore, this long-term follow-up study after an intervention programme is, to our knowledge, the first one. Only one of the published intervention studies report data one year after the childbirth (Olson et al., 2004), which makes a comprehensive comparison between different intervention studies impossible and can therefore be considered as a limitation. Another important limitation arises because the self-reported weight data are seldom equally exact as objective weight measurements would be. On the other hand, the women were asked to specify if the weight was newly measured or estimated and a majority of them in both groups stated that the weight was newly measured. Information of this kind can be considered more reliable than weights simply reported as estimated.

Our results encourage continuing the follow-up. The time of remaining effect of an intervention during pregnancy is still unknown and no other intervention studies have reported results from a long-term follow-up. In conclusion, attending a gestational weight gain restriction programme during pregnancy seems to have a positive effect on weight up to six years after the intervention. 


\section{Conflict of interest statement}

None of the authors had any conflicts of interest.

\section{Acknowledgements}

This study was supported by grants from The Health Research Council of the Southeast of Sweden and ALF, County Council of Östergötland.

\section{References}


AMORIM, A. R., ROSSNER, S., NEOVIUS, M., LOURENCO, P. M. \& LINNE, Y. 2007. Does excess pregnancy weight gain constitute a major risk for increasing long-term BMI? Obesity (Silver Spring), 15, 1278-86.

BLOMBERG, M. 2011. Maternal and neonatal outcomes among obese women with weight gain below the new institute of medicine recommendations. Obstet Gynecol, 117, 1065-70.

BLOMBERG, M. I. \& KALLEN, B. 2010. Maternal obesity and morbid obesity: the risk for birth defects in the offspring. Birth Defects Res A Clin Mol Teratol, 88, 35-40.

BODNAR, L. M., SIEGA-RIZ, A. M., SIMHAN, H. N., HIMES, K. P. \& ABRAMS, B. 2010. Severe obesity, gestational weight gain, and adverse birth outcomes. Am J Clin Nutr, 91, 1642-8.

CLAESSON, I. M., SYDSJO, G., BRYNHILDSEN, J., BLOMBERG, M., JEPPSSON, A., SYDSJO, A. \& JOSEFSSON, A. 2010. Weight after childbirth: a 2-year follow-up of obese women in a weight-gain restriction program. Acta Obstet Gynecol Scand, 90, 103-10.

CLAESSON, I. M., SYDSJO, G., BRYNHILDSEN, J., CEDERGREN, M., JEPPSSON, A., NYSTROM, F., SYDSJO, A. \& JOSEFSSON, A. 2008. Weight gain restriction for obese pregnant women: a case-control intervention study. BJOG, 115, 44-50.

DAVIS, E. M., BABINEAU, D. C., WANG, X., ZYZANSKI, S., ABRAMS, B., BODNAR, L. M. \& HORWITZ, R. I. 2013. Short Inter-pregnancy Intervals, Parity, Excessive Pregnancy Weight Gain and Risk of Maternal Obesity. Matern Child Health J.

GUELINCKX, I., DEVLIEGER, R., MULLIE, P. \& VANSANT, G. 2010. Effect of lifestyle intervention on dietary habits, physical activity, and gestational weight gain in obese pregnant women: a randomized controlled trial. Am J Clin Nutr, 91, 373-80.

GUNDERSON, E. P. \& ABRAMS, B. 1999. Epidemiology of gestational weight gain and body weight changes after pregnancy. Epidemiol Rev, 21, 261-75.

HARRIS, H. E., ELLISON, G. T. \& CLEMENT, S. 1999. Do the psychosocial and behavioral changes that accompany motherhood influence the impact of pregnancy on long-term weight gain? J Psychosom Obstet Gynaecol, 20, 65-79.

INSTITUTE OF MEDICINE. SUBCOMMITTEE ON NUTRITIONAL, S., WEIGHT GAIN DURING, P., INSTITUTE OF MEDICINE . SUBCOMMITTEE ON DIETARY, I. \& NUTRIENT SUPPLEMENTS DURING, P. 1990. Nutrition during pregnancy. Part I, Part II, Weight gain. Nutrient supplements, Washington, D.C., National Academy Press.

KINNUNEN, T. I., PASANEN, M., AITTASALO, M., FOGELHOLM, M., HILAKIVICLARKE, L., WEIDERPASS, E. \& LUOTO, R. 2007. Preventing excessive weight gain during pregnancy - a controlled trial in primary health care. Eur J Clin Nutr, 61, 884-91.

LINNE, Y., DYE, L., BARKELING, B. \& ROSSNER, S. 2004. Long-term weight development in women: a 15-year follow-up of the effects of pregnancy. Obes Res, 12, 1166-78.

MADDAH, M. \& NIKOOYEH, B. 2009. Weight retention from early pregnancy to three years postpartum: a study in Iranian women. Midwifery, 25, 731-7.

MAMUN, A. A., KINARIVALA, M., O'CALLAGHAN, M. J., WILLIAMS, G. M., NAJMAN, J. M. \& CALLAWAY, L. K. 2010. Associations of excess weight gain during pregnancy with long-term maternal overweight and obesity: evidence from 21 y postpartum follow-up. Am J Clin Nutr, 91, 1336-41.

MILLER, W. R. \& ROLLNICK, S. 2002. Motivational interviewing : preparing people for change, New York, Guilford Press. 
OHLIN, A. \& ROSSNER, S. 1996. Factors related to body weight changes during and after pregnancy: the Stockholm Pregnancy and Weight Development Study. Obes Res, 4, 271-6.

OLSON, C. M., STRAWDERMAN, M. S. \& REED, R. G. 2004. Efficacy of an intervention to prevent excessive gestational weight gain. Am J Obstet Gynecol, 191, 530-6.

OSTBYE, T., PETERSON, B. L., KRAUSE, K. M., SWAMY, G. K. \& LOVELADY, C. A. 2012. Predictors of postpartum weight change among overweight and obese women: results from the Active Mothers Postpartum study. J Womens Health (Larchmt), 21, 215-22.

PHELAN, S., PHIPPS, M. G., ABRAMS, B., DARROCH, F., SCHAFFNER, A. \& WING, R. R. 2011. Randomized trial of a behavioral intervention to prevent excessive gestational weight gain: the Fit for Delivery Study. Am J Clin Nutr, 93, 772-9.

POLLEY, B. A., WING, R. R. \& SIMS, C. J. 2002. Randomized controlled trial to prevent excessive weight gain in pregnant women. Int J Obes Relat Metab Disord, 26, 1494502.

QUINLIVAN, J. A., LAM, L. T. \& FISHER, J. 2011. A randomised trial of a four-step multidisciplinary approach to the antenatal care of obese pregnant women. Aust N Z J Obstet Gynaecol, 51, 141-6.

RASMUSSEN, K. M., YAKTINE, A. L. \& INSTITUTE OF MEDICINE . COMMITTEE TO REEXAMINE, I. O. M. P. W. G. 2009. Weight gain during pregnancy: reexamining the guidelines, Washington, DC, National Academies Press.

ROONEY, B. L. \& SCHAUBERGER, C. W. 2002. Excess pregnancy weight gain and longterm obesity: one decade later. Obstet Gynecol, 100, 245-52.

ROONEY, B. L., SCHAUBERGER, C. W. \& MATHIASON, M. A. 2005. Impact of perinatal weight change on long-term obesity and obesity-related illnesses. Obstet Gynecol, 106, 1349-56.

SHIRAZIAN, T., MONTEITH, S., FRIEDMAN, F. \& REBARBER, A. 2010. Lifestyle modification program decreases pregnancy weight gain in obese women. Am J Perinatol, 27, 411-4.

TENNANT, P. W., RANKIN, J. \& BELL, R. 2011. Maternal body mass index and the risk of fetal and infant death: a cohort study from the North of England. Hum Reprod, 26, 1501-11.

THANGARATINAM, S., ROGOZINSKA, E., JOLLY, K., GLINKOWSKI, S., DUDA, W., BOROWIACK, E., ROSEBOOM, T., TOMLINSON, J., WALCZAK, J., KUNZ, R., MOL, B. W., COOMARASAMY, A. \& KHAN, K. S. 2012. Interventions to reduce or prevent obesity in pregnant women: a systematic review. Health Technol Assess, 16, iii-iv, 1-191.

TSOI, E., SHAIKH, H., ROBINSON, S. \& TEOH, T. G. 2010. Obesity in pregnancy: a major healthcare issue. Postgrad Med J, 86, 617-23.

WOLFF, S., LEGARTH, J., VANGSGAARD, K., TOUBRO, S. \& ASTRUP, A. 2008. A randomized trial of the effects of dietary counseling on gestational weight gain and glucose metabolism in obese pregnant women. Int J Obes (Lond), 32, 495-501. 